\title{
Chemotherapy (Gemcitabine plus Carboplatin versus Paclitaxel plus Carboplatin) in Elderly Patients with Non-Small Cell Lung Cancer
}

\author{
Takanori Ayabe*, Masaki Tomita, Eiichi Chosa, Makoto Ikenoue, Yukie Shirasaki, \\ Kunihide Nakamura \\ Department of Surgery II, Faculty of Medicine, University of Miyazaki, Miyazaki, Japan \\ Email: ${ }^{*}$ tayabe@med.miyazaki-u.ac.jp
}

Received 11 February 2014; revised 6 March 2014; accepted 13 March 2014

Copyright (C) 2014 by authors and Scientific Research Publishing Inc.

This work is licensed under the Creative Commons Attribution International License (CC BY).

http://creativecommons.org/licenses/by/4.0/

(c) (i) Open Access

\section{Abstract}

Background: This retrospective study was to evaluate the efficacy and toxicity of gemcitabine plus carboplatin (GC regimen) and paclitaxel plus carboplatin (PC regimen) combination chemotherapy in elderly patients with non-small cell lung cancer. Methods: Seventy-four patients (GC regimen, $n=44 ; P C$ regimen, $n=30$ ) received gemcitabine at a dose of $1000 \mathrm{mg} / \mathrm{m}^{2}$ on days 1 and 8 , and carboplatin with the target dose of area under the curve (AUC) of 4 on day 8 every 28 days and paclitaxel at a dose of $70 \mathrm{mg} / \mathrm{m}^{2}$ on days 1,8 and 15, and carboplatin with the target dose of AUC of 5 on day 1 every 28 days. Patients were divided in two groups (younger one: $n=42,<70$ years old; elderly one: $n=32$, $\geq 70$ years old). Results: A total of 222 cycles of the treatment was administered. Seventy-one patients $(95.9 \%)$ completed the scheduled cycles. Two patients in the elderly group were discontinued (6.3\%) due to hematological toxicity and melena in the GC regimen and to grade 4 pneumonia in the $\mathrm{PC}$ regimen. The dose was reduced in 8 patients $(10.8 \%)$ due to grade 4 thrombocytopenia. Grade 3/4 neutropenia was not significantly observed in both groups (younger group: $24 / 42,57.1 \%$; elderly group: $19 / 32,59.4 \%, p=0.8471$ ). The nonhematological toxicities were mild in both groups. However, in the elderly group, grade $3 / 4$ thrombocytopenia was significantly observed in the GC group (GC: $5 / 17,29.4 \%$; PC: $0 / 15,0.0 \%, p=0.0222$ ). There was no treatment-related death. Conclusion: These results demonstrate that the GC and PC combination chemotherapies are efficacious and feasible regimens for lung cancer therapy, especially, both regimens should be considered as one of the standard therapies for elderly patients during lung cancer therapy.

*Corresponding author.

How to cite this paper: Ayabe, T., et al. (2014) Chemotherapy (Gemcitabine plus Carboplatin versus Paclitaxel plus Carboplatin) in Elderly Patients with Non-Small Cell Lung Cancer. Journal of Cancer Therapy, 5, 281-296. 
Keywords

Elderly; Lung Cancer; Chemotherapy; Paclitaxel; Gemcitabine; Carboplatin

\section{Introduction}

The incidence of lung cancer, the leading cause of cancer deaths, increases with age. More than 50\% of the cases of advanced non-small cell lung cancer (NSCLC) are diagnosed in patients over the age of 65 years, and recent Surveillance, Epidermiology and End Results (SEER) Program data in the United States show that patients aged 70 years or older account for 47\% of all lung cancers [1]. For example, in 1970 in Japan, $7.9 \%$ of the general population was 65 years older, which increased to $17.3 \%$ by 2000, and is estimated to reach $29.6 \%$ by 2030 [2]. As NSCLC is a common disease in the elderly population, the question of how best to treat elderly NSCLC patients will become increasingly important [3]. Chemotherapy in patients with advanced NSCLC improves survival, reduces disease-related symptoms, and improves the quality of life compared to the best supportive care [4].

Although platinum-based doublets involving newer agents, such as docetaxel, paclitaxel, gemcitabine, vinorelbine, and irinotecan, are the standard first-line chemotherapy for most patients with advanced NSCLC [5] [6], the use of these regimens in elderly patients remains a topic of debate [3]. The main reasons given for withholding standard platinum-based doublet regimens from elderly patients are the age-related impairment of organ functions, presence of potentially complicating comorbid conditions, and a lower ability to tolerate the potential toxicity of the combination chemotherapy than younger patients.

The efficacy of platinum-based chemotherapy in the treatment of advanced NSCLC has been demonstrated in several randomized trials and a significant meta-analysis [4]. However, elderly individuals have been underrepresented in such clinical trials, making it difficult to evaluate the efficacy and safety of current treatment options in this patient population [7]. The elderly, even those with a good performance status, are often considered unfit for aggressive chemotherapy, based on the assumptions that the risk of severe toxicity is exacerbated by age and that the benefits of such treatment are limited in terms of prognosis.

A meta-analysis of small randomized trials of patients with early stage NSCLC in the preceeding 30 years was performed in 1995 [4]. This analysis revealed a 5\% survival advantage at 5 years for patients with surgically resected early stage NSCLC treated with cisplatin-based chemotherapy compared to those patients only followed up after resection.

Most researchers agree that age-related issues do influence the clinician's evaluation of the elderly patients. Although age should be considered in the assessment of a patient, it is likely that common misconceptions regarding these patients may influence the treatment recommendations. The quality of life, long-term outlook, and survival in this population can be incorrectly perceived. These misperceptions can then influence the treatment decisions. A better understanding of how age affects prognosis, treatment options, and outcomes is necessary to avoid the undertreatment of this select population.

It is not yet clear whether platinum-based chemotherapy is feasible or available in neoadjuvant, adjuvant, and intensive chemotherapy settings for Japanese elderly patients. In clinical practice, we conducted trials to assess the efficacy and safety of gemcitabine plus carboplatin (GC regimen) and paclitaxel plus carboplatin (PC regimen) combination chemotherapy administered as a standard therapy for elderly surgical patients of NSCLC at a single institution.

\section{Patients and Methods}

\subsection{Patients}

From February 2006 to July 2009, a total of 74 patients who received neoadjuvant, adjuvant, and intensive doublet combinations chemotherapy of the gemcitabine plus carboplatin (GC regimen) or paclitaxel plus carboplatin (PC regimen), and who had received complete resection of the primary tumor and mediastinal lymph nodes in our department were evaluated. The above regimens were performed in daily clinical practice and approved by our hospital chemotherapy protocol committees but not by the institutional ethics committees. The characteristics of the 74 patients entered in this study are summarized in Tables 1 and 2 . The TNM classification 
Table 1. Patient characteristics.

\begin{tabular}{|c|c|c|c|c|c|c|c|c|}
\hline & & \multicolumn{2}{|c|}{ Overall $(n=74)$} & \multicolumn{2}{|c|}{ Younger group $(n=42)$} & \multicolumn{2}{|c|}{ Elderly group $(\mathrm{n}=32)$} & \multirow[b]{2}{*}{$\mathrm{p}$ value } \\
\hline & & No. of patients & (\%) & No. of patients & $(\%)$ & No. of patients & (\%) & \\
\hline \multirow{2}{*}{ Age } & Mean & $65.7 \pm 5.1$ & & $58.9 \pm 8.2$ & & $74.8 \pm 3.3$ & & \multirow{2}{*}{$<0.0001$} \\
\hline & range & $35-84$ & & $35-69$ & & $70-84$ & & \\
\hline \multirow{2}{*}{ Gender } & Male & 54 & 73 & 27 & 64.3 & 27 & 84.4 & \multirow{2}{*}{0.0542} \\
\hline & Female & 20 & 27 & 15 & 35.7 & 5 & 15.6 & \\
\hline \multirow{3}{*}{ ECOG-PS } & 0 & 64 & 86.5 & 40 & 95.2 & 24 & 75 & \multirow{3}{*}{0.0083} \\
\hline & 1 & 9 & 12.2 & 1 & 2.4 & 8 & 25 & \\
\hline & 2 & 1 & 1.4 & 1 & 2.4 & & & \\
\hline \multirow{4}{*}{ Surgery } & Lobectomy & 66 & 89.2 & 38 & 90.4 & 28 & 87.5 & \multirow{4}{*}{0.1522} \\
\hline & Pneumonectomy & 3 & 4.1 & 2 & 4.8 & 1 & 3.1 & \\
\hline & Partial resection & 2 & 2.7 & 2 & 4.8 & & & \\
\hline & None & 3 & 4.1 & & & 3 & 9.4 & \\
\hline \multirow{3}{*}{ Histology } & Adenocarcinoma & 64 & 86.5 & 39 & 92.8 & 25 & 78.1 & \multirow{3}{*}{0.1737} \\
\hline & $\begin{array}{l}\text { Squamous cell } \\
\text { carcinoma }\end{array}$ & 7 & 9.5 & 2 & 4.8 & 5 & 15.6 & \\
\hline & $\begin{array}{l}\text { Adenosquamous } \\
\text { cell carcinoma }\end{array}$ & 3 & 4.1 & 1 & 2.4 & 2 & 6.3 & \\
\hline \multirow{6}{*}{ Clinical stage } & IB & 2 & 2.7 & 2 & 4.8 & & & \multirow{6}{*}{0.0398} \\
\hline & IIA & 9 & 12.2 & 6 & 14.3 & 3 & 9.4 & \\
\hline & IIB & 6 & 8.1 & 1 & 2.4 & 5 & 15.6 & \\
\hline & IIIA & 25 & 33.8 & 16 & 38 & 9 & 28.1 & \\
\hline & IIIB & 8 & 10.8 & 7 & 16.7 & 1 & 3.1 & \\
\hline & IV & 24 & 32.4 & 10 & 23.8 & 14 & 43.8 & \\
\hline
\end{tabular}

ECOG-PS: Eastern Cooperative Oncology Group Performance Status.

Table 2. Treatment background.

\begin{tabular}{|c|c|c|c|c|c|}
\hline & & Overall $(n=74)$ & Younger group $(n=42)$ & Elderly group $(\mathrm{n}=32)$ & $\mathrm{p}$ value \\
\hline \multirow{3}{*}{ Chemotherapy } & Adjuvant & 44 & 31 & 13 & \multirow{3}{*}{0.0094} \\
\hline & Recurrence & 25 & 10 & 15 & \\
\hline & Intensive, Induction & 5 & 1 & 4 & \\
\hline \multirow{2}{*}{ Regimen } & GEM + CBDCA & 44 & 27 & 17 & \multirow{2}{*}{0.3333} \\
\hline & $\mathrm{PTX}+\mathrm{CBDCA}$ & 30 & 15 & 15 & \\
\hline Planned cycles & $1 / 2 / 3 / 4 / 5 / 6$ cycles & $3 / 33 / 8 / 23 / 0 / 7$ & $3 / 19 / 5 / 13 / 0 / 2$ & 0/14/3/10/0/5 & 0.3230 \\
\hline Received cycles & 1/2/3/4/5/6 cycles & 4/33/9/21/1/6 & $3 / 19 / 6 / 12 / 0 / 2$ & $1 / 14 / 3 / 9 / 1 / 4$ & 0.6133 \\
\hline \multirow{4}{*}{ Compliance } & Completed & 71(95.9\%) & $41(97.6 \%)$ & $30(93.8 \%)$ & \multirow{4}{*}{0.2304} \\
\hline & Discontinued & $2(2.7 \%)$ & $0(2.4 \%)$ & $2^{*}(6.3 \%)$ & \\
\hline & Dose reduction & $8(10.8 \%)$ & $5(11.9 \%)$ & $3(9.4 \%)$ & \\
\hline & Delayed & $3(4.1 \%)$ & $3(7.1 \%)$ & $0(0.0 \%)$ & \\
\hline $\begin{array}{c}\text { Response to } \\
\text { treatment } \\
\text { (RECIST) }\end{array}$ & Partial response (PR) & 11 & 2 & 9 & \multirow[t]{2}{*}{0.1100} \\
\hline$(\mathrm{n}=30)$ & Stable disease (SD) & 19 & 9 & 10 & \\
\hline Toxicities & $\geq$ Grade $3 / 4$ & $43(58.1 \%)$ & $23(54.8 \%)$ & $20(62.5 \%)$ & 0.5040 \\
\hline
\end{tabular}

${ }^{*} \mathrm{G} 4$ hematologic toxicity and melena in GC regimen, G4 pneumonia in PC regimen. 
is based on the Union for International Cancer Control (UICC) [8]. The histological analysis of the tumor was based on the World Health Organization classification for cell types [9]. Patients with histologically documented NSCLC and pathologically staged were eligible to receive the chemotherapy.

\subsection{Each Patient Had to Meet the Following Eligibility Criteria}

Pathological stage from IB to IV diagnosed with complete resection, Eastern Cooperative Oncology Group Performance Status of 0,1 or 2 , adequate bone marrow function (total leukocyte count $\geq 4.0 \times 10^{9}$, hemoglobin concentration $\geq 10.0 \mathrm{~g} / \mathrm{dl}$, platelet count $\geq 100 \times 10^{9} / \mathrm{L}$ ), adequate liver and renal functions (serum transaminase $\leq 2$ times normal value; serum creatinine $\leq 1.5$ times normal value), partial pressure of arterial oxygen $\left(\mathrm{paO}_{2}\right) \geq$ 60 torr, past history of severe allergic reaction to drugs, interstitial pneumonia identified by computed-tomography of chest, cirrhosis, or other serious complications, such as uncontrolled angina pectoris, myocardial infarction within 3 months, heart failure, uncontrolled diabetes mellitus or hypertension, and uncontrolled massive pleural effusion or ascites, no postoperative complications, able to undergo first course treatment in an inpatients setting within 4 to 8 weeks after surgery, and written informed consent. All patients provided written informed consent before the treatment.

\subsection{Treatment Schedule}

All patients received one of the two treatment groups by attending doctors' direction and/or patients' favorable selection depending on the regimen's toxicities. The body surface area was calculated using the DuBois equation. The carboplatin dosage calculation was based on the glomerular filtration rate according to the Calvert formula [10], and evaluated by the Cockcroft-Gault equation [11]. The administration of the carboplatin dosage was adjusted prior to each cycle through re-determination of the glomerular filtration rate.

\subsubsection{Gemcitabine plus Carboplatin Regimen (GC Group)}

Gemcitabine (Gemzar, Eli Lilly Japan K.K., Kobe, Japan) was administered at a dose of $1000 \mathrm{mg} / \mathrm{m}^{2}$ on days 1 and 8, and carboplatin (Paraplatin, Bristol-Myers K.K., Tokyo, Japan) with the target dose of area under the curve (AUC) of 4 on day 8 every 28 days. Premedication was intravenously performed with the drip infusion of $100 \mathrm{ml}$ of isotonic sodium chloride solution containing $8 \mathrm{mg}$ of dexamethasone sodium phosphate and $3 \mathrm{mg}$ of granisetron hydrochloride. An infusion pump was used to ensure the exact infusion time. On days 1 and 8 , the intravenous (i.v.) administration of $1000 \mathrm{mg} / \mathrm{m}^{2}$ gemcitabine mixed in $100 \mathrm{ml}$ of isotonic sodium chloride solution was performed by drip infusion for 30 minutes. On day 8, carboplatin with the calculated dose of the AUC mixed in $250 \mathrm{ml}$ of a $5 \%$ glucose solution was administered for 1 hour, following the drip infusion of gemcitabine.

\subsubsection{Paclitaxel and Carboplatin Regimen (PC Group)}

Paclitaxel (Paclitaxel, Bristol-Myers K.K., Tokyo, Japan) was administered at a dose of $70 \mathrm{mg} / \mathrm{m}^{2}$ on days 1, 8 and 15, and carboplatin (Paraplatin, Bristol-Myers K.K., Tokyo, Japan) with the target dose of AUC of 5 on day 1 every 28 days. As a premedication, $50 \mathrm{mg}$ of diphenhydramine hydrochloride was intravenously infused. The drip infusion of $50 \mathrm{ml}$ of an isotonic sodium chloride solution containing $8 \mathrm{mg}$ of dexamethasone sodium phosphate and $50 \mathrm{mg}$ of ranitidine hydrochloride and $10 \mathrm{mg}$ of azasetron hydrochloride were performed. After the administration of seventy $\mathrm{mg} / \mathrm{m}^{2}$ of paclitaxel in $250 \mathrm{ml}$ of a $5 \%$ glucose solution for over 1 hour, carboplatin with the calculated dose of the AUC mixed in $250 \mathrm{ml}$ of a $5 \%$ glucose solution was intravenously infused for 1 hour.

Each treatment was recommended for four cycles as a standard course. Patients could plan their scheduled cycle number between 1 to 6 and also refuse the treatment unless they met the criteria for an experienced unacceptable toxicity. Full supportive therapy, corticosteroids, anticonvulsants and antibiotics were given as needed. No routine use of heatopoietic growth factors was planned. No prophylactic antibiotics were used. All patients were treated on an inpatient basis.

\subsubsection{The Exclusion Criteria}

The exclusion criteria included serious infection, fever $\left(\geq 38^{\circ} \mathrm{C}\right)$, impairments of the organ function (bone marrow, central nervous and cardiovascular system, liver, kidneys, interstitial pneumonia, DIC), patient’s refusal 
and attending doctor's decision.

\subsection{Dose Modification}

Dose adjustments during the treatment were based on the judgment of the respective physicians in-charge, but, as a rule, when grade 3 or more severe nonhematotoxicity or grade 4 hematotoxicity appeared, the doses of the anticancer drugs were reduced. The complete blood count and biochemistry were usually examined at least once or twice per week.

On the scheduled day- 1 treatment, if the total leukocyte count and absolute neutrophil count (ANC) was $\leq 3.0$ $\times 10^{9} / 1$ and $\leq 1.5 \times 10^{9}$ per liter and/or platelet count $\leq 100 \times 10^{9}$ per liter, respectively, the chemotherapy doses were either delayed (for up to 2 weeks) or reduced by $20 \%$ - 25\% gemcitabine: $1000 \mathrm{mg} / \mathrm{m}^{2}$ to $800 \mathrm{mg} / \mathrm{m}^{2}$, AUC of carboplatin from 4 to 3, paclitaxel: from $70 \mathrm{mg} / \mathrm{m}^{2}$ to $60 \mathrm{mg} / \mathrm{m}^{2}$, AUC of carboplatin from 5 to 4 to al- low recovery from the hematological toxicity.

On the scheduled day- 8 treatment, if the total leukocyte count and ANC was $\leq 1.0 \times 10^{9}$ per liter and $\leq 0.5 \times$ $10^{9}$ per liter and/or the platelet count $\leq 75 \times 10^{9}$ per liter, respectively, and if these parameters did not improve sufficiently, then the day-8 administrations of the drugs were postponed and omitted. A 2-week delay in initiating the subsequent course was allowed. Patients, who cannot recover from the hematological toxicity (ANC $\geq$ $1.0 \times 10^{9}$ per liter and/or platelets $\geq 75 \times 10^{9}$ per liter) within 2 weeks were removed from the treatment.

For patients of the delayed day 8 and/or of the no recovery within 2 weeks for any $\geq$ grade 2 impairments of the organ function (hepatic, renal, cardiovascular, pulmonary and nervous system) and/or $\geq$ grade 3 nonhematological toxicities (excluding nausea, vomiting, anorexia, fatigue and alopecia), the doses of the next cycle were reduced by $20 \%-25 \%$. If these toxicities persisted after 6 weeks from day 1 of the previous cycle, then the treatment regimen was discontinued.

The next cycle was discontinued in the case of $\geq$ grade 3 impairments on the organ function (hepatic, renal, cardiovascular, pulmonary and nervous system) and/or $\geq$ grade 4 nonhematological toxicities (nausea, vomiting, anorexia, fatigue and alopecia). The subsequent course of chemotherapy was begun if patients had a leukocyte count of $\geq 3.0 \times 10^{9} / 1$, ANC $\geq 1.5 \times 10^{9} / 1$, platelet count $\geq 100 \times 10^{9} / 1$, creatinine $\geq 1.5 \mathrm{mg} / \mathrm{dl}$, alanine aminotransferase and aspartate aminotransferase (AST/ALT) levels $\leq 2.5$ times the normal upper limit, and total bilirubin $\leq 1.5$ times normal upper limit.. Both regimens were repeated every 4 weeks.

Regarding the use of the granulocyte colony-stimulating factor (G-CSF), patients did not receive the prophylactic G-CSF during any cycle. The use of G-CSF (100 $\mu \mathrm{g}$ /day, subcutaneous injection) was allowed only for patients who had the total leukocyte count $\leq 1.0 \times 10^{9} /$ liter, ANC $\leq 0.5 \times 10^{9} / \mathrm{l}$, neutropenic fever, or documented infections with febrile neutropenia.

\subsection{Toxicity}

Prior to the chemotherapy, all patients provided a complete medical history and underwent a physical examination. Patients were monitored weekly throughout treatment by physical examination, recording of toxic effects, complete blood cell counts, and blood chemistry. These patients were examined for the patient background characteristics, adverse events and treatment compliance. Adverse events (AE) were evaluated for 4 weeks after the completion of the chemotherapy according to the Common Terminology Criteria for Adverse Events Version. 3.0 (CTCAE v3.0). The CTCAE v3.0 displays Grades 1 through 5 with unique clinical descriptions of severity for each adverse event based on this general guideline: Grade 1, mild AE; Grade 2, moderate AE; Grade 3, severe AE; Grade 4, life-threatening or disabling AE; Grade 5, Death related to AE. Grade 3/4 thrombocytopenia (grade 3, <50.0 - 25.0 $\times 10^{9} /$; grade $4,<25.0 \times 10^{9} /$ l) and grade $1 / 2$ alopecia (grade 1 , thinning or patchy; grade 2 , complete) were defined.

\subsection{Treatment Evaluation}

Tumor responses were classified according to the Response Evaluation Criteria in Solid Tumors [12]. In the target lesions, a complete response (CR) was defined as the complete disappearance of all target lesions for a minimum of 4 weeks during which no new lesions appeared. A partial response (PR) was defined as a $>30 \%$ decrease in the sum of the greatest dimensions of the target lesions for a minimum of 4 weeks. A progressive disease (PD) was defined as a $>20 \%$ increase in the sum of the greatest dimensions of the target lesions or the ap- 
pearance of $>1$ new lesion(s). A stable disease (SD) was defined as not a sufficient increase to quality for PD for a minimum of 6 weeks. The response duration in patients who achieved a CR or PR was measured from the start of the treatment to the date of the disease progression.

\subsection{Statistical Analysis}

Statistical differences in the toxicities between the two regimens were calculated using the Chi-square $\left(\chi^{2}\right)$ test. A p value less than 0.05 was considered to be statistically significant.

\section{Results}

\subsection{Patient Characteristics}

A total of 74 patients (42 patients in the younger group and 32 in the elderly group) received chemotherapy in our department and summarized in Table 1 . The majority of patients were males (54/74, 73.0\%) with the median age of $65.7 \pm 5.1$ years (range $35-84$ ). In the younger group, the median age was $58.9 \pm 8.2$ years (range 35 - 69), and $74.8 \pm 3.3$ years (range 70 - 84) in the elderly group. The ECOG performance status was 0 in 40 patients (40/42, 95.2\%) in the younger group and 24 in 32 patients $(24 / 32,75.0 \%)$ in the elderly group. A lobectomy was performed in 66 patients (66/74, 89.2\%) and a pneumonectomy was done in 3 patients (3/74, 4.1\%). Tumor histology included 64 patients with adenocarcinoma (86.5\%), 7 patients with squamous cell carcinoma (9.5\%) and 3 patients with adenosquamous cell carcinoma (4.1\%). There were 2 patients with stage IB (2.7\%), 9 patients with stage IIA (12.2\%), 6 patients with stage IIB (8.1\%), 25 patients with stage IIIA (33.8\%), 8 patients with stage IIIB (10.8\%), and 24 patients with stage IV diseases (32.4\%).

\subsection{Treatment Background}

A total of 222 chemotherapy cycles were administered (119 cycles in the younger group: median, 2.8; range, 1 6, 103 cycles in the elderly group: median, 3.2; range, 1 - 6) as listed in Table 2. On compliance, forty-one of 42 patients (97.6\%) in the younger group and thirty of 32 patients $(93.8 \%)$ in the elderly group completed the planned cycles, the remaining 2 patients in the elderly group did not complete the course due to grade 4 pneumonia and hematologic toxicity and melena. Five patients (11.9\%) in the younger group and three patients $(9.4 \%)$ in the elderly group received a dose reduction in the next course. Three patients $(7.1 \%)$ in the younger group delayed the course.

\subsection{Treatment Response}

In the younger group, there were 2 PRs for an overall response rate of $18.2 \%(2 / 11)$ as listed in Table 2. In addition, 9 patients $(81.8 \%, 9 / 11)$ had SDs. In the elderly group, there were 9 PRs for an overall response rate of $47.4 \%$ (9/19). There were 10 patients $(52.6 \%, 10 / 19)$ with SD.

\subsection{Toxicity}

For the grade 3/4 toxicities (Table 2), the younger group had 23 patients (23/42, 54.8\%) that showed a lower incidence compared to twenty patients in the elderly group (20/32, 62.5\%). Overall, forty-three patients in both groups showed that grade $3 / 4$ toxicities (43/74, 58.1\%). The hematological toxicities are shown in Table 3 . The grade $3 / 4$ neutropenia was similarly observed in both groups (younger group: 24/42, 57.1\%; elderly group: $19 / 32,59.4 \%, p=0.8471$ ). The grade $3 / 4$ anemia was similarly observed in both groups (younger group: $3 / 42$, 7.1\%; elderly group: $2 / 32,6.3 \%, p=0.8795$ ). The grade $3 / 4$ thrombocytopenia was similarly seen in 9 patients $(21.4 \%)$ of the younger group compared to 5 patients $(15.6 \%)$ of the elderly group $(\mathrm{p}=0.5277)$. The grade $3 / 4$ febrile neutropenia was seen in 3 patients (7.1\%) of the younger group compared to 2 patients (6.3\%) of the elderly group $(\mathrm{p}=0.8795)$.

The nonhematological toxicities are mild except for infection as shown in Table 4. However, grade 4 pneumonia was observed in 1 patient (1/32, 3.1\%) of the elderly group compared to none in the younger group. Grade 1/2 nausea, anorexia, fatigue were frequently observed in both groups. Grade 1/2 nausea in the younger group were similarly observed when compared to those of the elderly group (younger group: 24/42, 57.1\%; elderly group: $18 / 32,56.3 \%, p=0.9388$ ). Grade $1 / 2$ anorexia in the younger group was similarly observed when 
Table 3. Summary of hematological toxicities.

\begin{tabular}{ccccccccc}
\hline & \multicolumn{4}{c}{ Younger group $(\mathrm{n}=42)$} & \multicolumn{3}{c}{ Elderly group $(\mathrm{n}=32)$} \\
\cline { 2 - 8 } & \multicolumn{3}{c}{$\mathrm{n}(\%$ of patients) } & \multicolumn{2}{c}{$\mathrm{n}(\%$ of patients) } & G 3/4 \\
\hline Toxicity & G 1/2 & G 3/4 & G 3/4 (\%) & G 1/2 & G 3/4 & G 3/4 (\%) & p value \\
Leukopenia & 36 & 2 & 4.8 & 24 & 4 & 12.5 & 0.227 \\
Neutropenia & 17 & 24 & 57.1 & 9 & 19 & 59.4 & 0.8471 \\
Anemia & 11 & 3 & 7.1 & 15 & 2 & 6.3 & 0.8795 \\
Thrombocytopenia & 10 & 9 & 21.4 & 9 & 5 & 15.6 & 0.5277 \\
Febrile neutropenia & 5 & 3 & 7.1 & 0 & 2 & 6.3 & 0.8795 \\
\hline
\end{tabular}

Table 4. Summary of nonhematological toxicities.

\begin{tabular}{|c|c|c|c|c|c|c|c|}
\hline \multirow[b]{3}{*}{ Toxicity } & \multirow{2}{*}{\multicolumn{3}{|c|}{$\begin{array}{c}\text { Younger group }(\mathrm{n}=42) \\
n \text { (\% of patients) }\end{array}$}} & \multirow{2}{*}{\multicolumn{3}{|c|}{$\begin{array}{c}\text { Elderly group }(\mathrm{n}=32) \\
\mathrm{n}(\% \text { of patients })\end{array}$}} & \multirow{3}{*}{$\begin{array}{c}\text { G1/2 } \\
\text { p value }\end{array}$} \\
\hline & & & & & & & \\
\hline & G $1 / 2$ & \multirow{2}{*}{$\begin{array}{c}\text { G } 3 / 4 \\
0\end{array}$} & \multirow{2}{*}{$\begin{array}{c}\text { G } 1 / 2(\%) \\
57.1\end{array}$} & \multirow{2}{*}{$\begin{array}{c}\text { G } 1 / 2 \\
18\end{array}$} & \multirow{2}{*}{$\begin{array}{c}\text { G } 3 / 4 \\
0\end{array}$} & \multirow{2}{*}{$\begin{array}{c}\text { G } 1 / 2(\%) \\
56.3\end{array}$} & \\
\hline Nausea & 24 & & & & & & 0.9388 \\
\hline Vomiting & 5 & 0 & 11.9 & 3 & 0 & 9.4 & 0.7284 \\
\hline Anorexia & 33 & 0 & 78.6 & 25 & 0 & 78.1 & 0.9631 \\
\hline Fatigue & 32 & 0 & 76.2 & 26 & 0 & 81.3 & 0.6004 \\
\hline Diarrhea & 4 & 0 & 9.5 & 0 & 0 & 0 & 0.0727 \\
\hline Constipation & 14 & 0 & 33.3 & 13 & 0 & 40.6 & 0.5186 \\
\hline AST/ALT & 20 & 0 & 47.6 & 13 & 0 & 40.6 & 0.5487 \\
\hline Creatinine & 1 & 0 & 2.4 & 3 & 0 & 9.4 & 0.1875 \\
\hline Neuropathy & 0 & 0 & 0 & 0 & 0 & 0 & - \\
\hline Pain, joint & 3 & 0 & 7.1 & 1 & 0 & 3.1 & 0.4489 \\
\hline Pain, muscle & 1 & 0 & 2.4 & 3 & 0 & 9.4 & 0.1875 \\
\hline Skin rash & 5 & 0 & 11.9 & 2 & 0 & 6.3 & 0.4102 \\
\hline Alopecia & 12 & 0 & 28.6 & 14 & 0 & 43.8 & 0.1754 \\
\hline Infection & 1 & 0 & 2.4 & 0 & $1^{*}$ & 0 & 0.3795 \\
\hline Fever & 6 & 0 & 14.3 & 3 & 0 & 9.4 & 0.522 \\
\hline Others & 3 & 0 & 7.1 & 1 & 0 & 3.1 & 0.4489 \\
\hline
\end{tabular}

ALT/AST: alanine aminotransferase and aspartate aminotransferase; ${ }^{*} \mathrm{G} 4$ pneumonia.

compared to those of the elderly group (yoguner group: 33/42, 78.6\%; elderly group: $25 / 32,78.1 \%, p=0.9631$ ) Grade $1 / 2$ fatigue in the younger group was similarly observed compared to those of the elderly group (younger group: $32 / 42,76.2 \%$; elderly group: $26 / 32,81.3 \%, p=0.6004)$. Grade $1 / 2$ constipation was observed in the younger group (younger group: 14/42, 33.3\%; elderly group: 13/32, 40.6\%, $p=0.5186$ ). Grade 1/2 alanine aminotransferase and aspartate aminotransferase (ALT/AST) in the younger group was similarly observed when compared to those of the elderly group (younger group: 20/42, 47.6\%; elderly group: $13 / 32,40.6 \%, p=0.5487$ ). Grade $1 / 2$ alopecia was observed in the younger group (younger group: 12/42, 28.6\%; elderly group: 14/32, $43.8 \%, p=0.1754)$. For the other toxicities, in the GC regimen, they were observed in 3 patients with headaches in the younger group and in 1 patient with difficulty in hearing in the elderly group. In the PC regimen, in the 
elderly group, grade 4 pneumonia was observed in 1 patient. For the other toxicities, they were observed in 1 patient with a headache and hematuria. The overall grade $1 / 2$ non-hematologic toxicities were mild. There was no treatment-related death.

\subsection{Toxicity of GC and PC Regimens in Elderly Group}

For the grade 3/4 toxicities, the PC regimen had 11 patients (11/15, 73.3\%) that showed a higher incidence compared to 9 patients of the GC regimen (9/17, 52.9\%). In both regimens in the elderly group, overall, twenty patients showed grade $3 / 4$ toxicities (20/32, 62.5\%). The hematological toxicities are shown in Table 5 . The grade 3/4 neutropenia was similarly observed in both groups (GG: 9/17, 52.9\%; PC: 10/15, 66.7\%, p = 0.4302). The grade $3 / 4$ anemia was similarly observed in both groups (GC regimen: 1/17, 5.9\%; PC regimen: $1 / 15,6.7 \%$, $\mathrm{p}=0.9271)$. However, the grade $3 / 4$ thrombocytopenia was significantly higher in 5 patients $(29.4 \%)$ of the GC regimen compared to 0 patient $(0 \%)$ of the PC regimen $(\mathrm{p}=0.0222)$. The grade $3 / 4$ febrile neutropenia was seen in 1 patient (5.9\%) of the GC regimen compared to 1 patient $(6.7 \%)$ of the PC regimen $(\mathrm{p}=0.9271)$.

The nonhematological toxicities are mild except for infection as shown in Table 6. However, grade 4 pneumonia was observed in 1 patient $(1 / 15,6.7 \%)$ of the PC regimen compared to none in the GC regimen. Grade $1 / 2$ nausea, anorexia, fatigue were frequently observed in both groups. Grade 1/2 nausea in the GC regimen were similarly observed when compared to those of the PC regimen (GC: 8/17, 47.1\%; PC: 10/15, 66.7\%, $\mathrm{p}=$ 0.2645). Grade 1/2 anorexia in the PC regimen were higher when compared to those of the GC regimen (GC: 11/17, 64.7\%; PC: $14 / 15,93.3 \%, p=0.0506$ ). Grade $1 / 2$ fatigue in the GC regimen was similarly observed when compared to those of the PC regimen (GC: 15/17, 88.2\%; PC: 11/15, 73.3\%, p = 0.2811). Grade 1/2 constipation was observed in the GC regimen (GC: $8 / 17,47.1 \%$; PC: 5/15, 33.3\%, p = 0.4302). Grade 1/2 alanine aminotransferase and aspartate aminotransferase (ALT/AST) in the GC regimen were significantly higher compared to those of the PC regimen (GC: 10/17, 58.8\%; PC: 3/15, 20.0\%, p = 0.0256). Grade 1/2 alopecia was significantly observed in the PC regimen (GC: 0/17, 0\%; PC: 14/15, 93.3\%, $\mathrm{p}<0.0001$ ). For the other toxicities, in the GC regimen, they were observed in 1 patient with difficulty in hearing. The overall grade $1 / 2$ non-hematologic toxicities were mild. There was no treatment-related death.

\section{Discussion}

Since the end of World War II, there has been a dramatic expansion in the world's population; in addition to the post-war generation of baby boomers, advances in health and healthcare delivery have led to an increased life expectancy. At the same time, both eastern and western epidemiological studies show an increased incidence of lung cancer in elderly patients [1] [13]-[15]. Given that more than 50\% of lung cancer patients are diagnosed over the age of 65 and about 30\% over the age of 70, lung cancer has become the disease of aged people [3] [16]. Lung cancer treatment in the elderly is increasingly common and a challenging concern for physicians. As the population continues to age and medical advances continue to increase life expectancy, physician care for the elderly patient with NSCLC will become more common. Many factors influence the care for the elderly, including our own experiences, biases, and misconceptions as they relate to age, quality of life, and life expectancy. Identifying and evaluating these factors is essential for avoiding these pitfalls, and is critical to providing the

\begin{tabular}{|c|c|c|c|c|c|c|c|}
\hline \multirow[b]{3}{*}{ Toxicity } & \multirow{2}{*}{\multicolumn{3}{|c|}{$\begin{array}{c}\text { GEM + CBDCA regimen }(\mathrm{n}=17) \\
\mathrm{n}(\% \text { of patients })\end{array}$}} & \multirow{2}{*}{\multicolumn{3}{|c|}{$\begin{array}{c}\text { PTX + CBDCA regimen }(n=15) \\
n \text { ( } \% \text { of patients })\end{array}$}} & \multirow{3}{*}{ G3/4 } \\
\hline & & & & & & & \\
\hline & G $1 / 2$ & G 3/4 & G 3/4 (\%) & G $1 / 2$ & G $3 / 4$ & G 3/4 (\%) & \\
\hline Leukopenia & 11 & 3 & 17.6 & 13 & 1 & 6.7 & 0.3486 \\
\hline Neutropenia & 5 & 9 & 52.9 & 4 & 10 & 66.7 & 0.4302 \\
\hline Anemia & 10 & 1 & 5.9 & 5 & 1 & 6.7 & 0.9271 \\
\hline Thrombocytopenia & 6 & 5 & 29.4 & 3 & 0 & 0 & 0.0222 \\
\hline Febrile neutropenia & 0 & 1 & 5.9 & 0 & 1 & 6.7 & 0.9271 \\
\hline
\end{tabular}


Table 6. Summary of nonhematological toxicities in elderly group.

\begin{tabular}{|c|c|c|c|c|c|c|c|}
\hline \multirow[b]{3}{*}{ Toxicity } & \multirow{2}{*}{\multicolumn{3}{|c|}{$\begin{array}{c}\text { GEM + CBDCA regimen }(\mathrm{n}=17) \\
\mathrm{n}(\% \text { of patients })\end{array}$}} & \multirow{2}{*}{\multicolumn{3}{|c|}{$\begin{array}{c}\text { PTX + CBDCA regemen }(\mathrm{n}=15) \\
\mathrm{n}(\% \text { of patients })\end{array}$}} & \multirow{3}{*}{$\begin{array}{c}\text { G 1/2 } \\
p \text { value }\end{array}$} \\
\hline & & & & & & & \\
\hline & G $1 / 2$ & \multirow{2}{*}{$\begin{array}{c}\text { G } 3 / 4 \\
0\end{array}$} & \multirow{2}{*}{$\begin{array}{c}\text { G } 1 / 2(\%) \\
47.1\end{array}$} & \multirow{2}{*}{$\begin{array}{c}\mathrm{G} 1 / 2 \\
10\end{array}$} & \multirow{2}{*}{$\begin{array}{c}\mathrm{G} 3 / 4 \\
0\end{array}$} & \multirow{2}{*}{$\begin{array}{c}\text { G } 1 / 2(\%) \\
66.7\end{array}$} & \\
\hline Nausea & 8 & & & & & & 0.2645 \\
\hline Vomiting & 1 & 0 & 5.9 & 2 & 0 & 13.3 & 0.4705 \\
\hline Anorexia & 11 & 0 & 64.7 & 14 & 0 & 93.3 & 0.0506 \\
\hline Fatigue & 15 & 0 & 88.2 & 11 & 0 & 73.3 & 0.2811 \\
\hline Diarrhea & 0 & 0 & 0 & 0 & 0 & 0 & - \\
\hline Constipation & 8 & 0 & 47.1 & 5 & 0 & 33.3 & 0.4302 \\
\hline ALT/AST & 10 & 0 & 58.8 & 3 & 0 & 20 & 0.0256 \\
\hline Creatinine & 2 & 0 & 11.8 & 1 & 0 & 6.7 & 0.6215 \\
\hline Neurolopathy & 0 & 0 & 0 & 0 & 0 & 0 & - \\
\hline Pain, joint & 1 & 0 & 5.9 & 0 & 0 & 0 & 0.3399 \\
\hline Pain, muscle & 1 & 0 & 5.9 & 2 & 0 & 13.3 & 0.4705 \\
\hline Skin rash & 1 & 0 & 5.9 & 1 & 0 & 6.7 & 0.9271 \\
\hline Alopecia & 0 & 0 & 0 & 14 & 0 & 93.3 & $<0.0001$ \\
\hline Infection & 0 & 0 & 0 & 0 & $1^{*}$ & 0 & - \\
\hline Fever & 1 & 0 & 5.9 & 2 & 0 & 13.3 & 0.4705 \\
\hline Others (Hearing) & 1 & 0 & 5.9 & 0 & 0 & 0 & 0.3399 \\
\hline
\end{tabular}

ALT/AST: alanine aminotransferase and aspartate aminotransferase; ${ }^{*} \mathrm{G} 4$ pneumonia.

best care to these patients. Clinical data obtained in a younger population cannot be automatically extrapolated to the great majority of nonselected elderly patients with NSCLC. Elderly patients have more comorbidities and tend to tolerate toxic medical treatments less well than their younger counterparts. This patient population is at risk of both empirical undertreatment resulting in poor survival or excessive toxicity from standard therapy. Some of the data available today are based on retrospective studies of trials which included patients with good performance status and of all ages.

Elderly patients are often present with medical and physiologic characteristics [17]-[20] that make the selection of their optimal treatment more challenging. Unfortunately, because of this, these patients are at risk of being undertreated [21]. Aging objectively determines physiologic changes in functional status, organ function, and drug pharmacokinetics. Furthermore, concomitant diseases, which may significantly affect functional status, general health, and tumor symptoms, are frequently present in this patient population [20]. These comorbidities may also result in a higher prevalence of polypharmacy and related risk [21]. In current practice, the elderly are often excluded from participation in clinical trials and receive untested or inadequate treatment [22]. In fact, although most phase II and III trials now do not have an upper age limit, only a minority of elderly patients are enrolled in these trials. Retrospective analyses of ordinary trials without age-specific entry criteria are potentially biased by the intrinsic selection that govern enrollment. Single-agent chemotherapy with third-generation agents is to be considered the routine standard for the care of unselected patients.

Single-agent chemotherapy was one of the first approaches to being evaluated in this setting, and third-generation monotherapy with vinorelbine, gemcitabine and taxanes (paclitaxel and docetaxel) is currently the approach supported by prospective, elderly-specific clinical data, by the American Society of Clinical Oncology (ASCO) guideline and International Experts panels in unselected patients [3] [23]. Several factors should be considered by the clinician when the drug to be administered is chosen; this choice should take into account the expected toxicity profile of the agent, pharmacokinetics, organ function, and comorbidities. After an appropriate 
communication process, patients' preferences may also facilitate the decision making process. The landmark phase III trial in 191 patients (the Elderly Lung Cancer Vinorelbine Italian Study, or ELVIS study) showed that single-agent vinorelbine improved the quality of life and survival compared with supportive care alone (median survival, 27 versus 21 weeks, $p=0.04$ ) [24]. Several phase II trials showed the role of gemcitabine in this setting with an overall response rate of $18 \%$ - 38\%, a median survival of 6.8 - 9 months, and a predictable and acceptable toxicity profile [25]. Also, paclitaxel and docetaxel have demonstrated both activity and tolerability in the treatment of advanced NSCLC. In an effort to reduce the toxicity, weekly regimens of single-agent paclitaxel have been investigated in three phase II studies with response rates ranging from $3 \%$ to $23 \%$, median survival of 6.8 - 10.3 months, and tolerable toxicity profiles [26]. Regarding docetaxel, a randomized phase III trial (with 182 patients enrolled) showed that docetaxel, administered at $60 \mathrm{mg} / \mathrm{m}^{2}$ every 21 days, was at least as good as vinorelbine in terms of median survival in the treatment of elderly advanced NSCLC patients (14.3 months versus 9.9 months with docetaxel and vinorelbine, respectively; hazard ratio [HR], 0.780; 95\% confidence interval [CI], $0.561-1.085 ; \mathrm{p}=0.138)$ [27]. Docetaxel improved the progression-free survival (PFS) (5.5 months versus 3.1 months; $p<0.001)$ and response rate $(22.7 \%$ versus $9.9 \% ; p=0.019)$ versus vinorelbine, but was associated with more grade 3 - 4 neutropenia ( $82.9 \%$ for docetaxel; $69.2 \%$ for vinorelbine; $\mathrm{p}=0.031$ ). Thus, docetaxel can be considered a reasonable option in this clinical setting.

Nonplatinum-based combinations have been developed. The most studied regimen is gemcitabine plus vinorelbine. The largest randomized phase III trial, called MILES (Multicenter Italian Lung Cancer in the Elderly Study), accrued about 700 elderly patients and showed that the combination of vinorelbine plus gemcitabine was no more effective than single-agent vinorelbine or gemcitabine in the treatment of elderly patients with advanced NSCLC [20]. The median survival was 36, 28 and 30 weeks, and the probability of being alive after 1 year was $38 \%, 28 \%$ and $30 \%$, for vinorelbine, gemcitabine and the combination, respectively. Although the quality of life was similar across the three treatment arms, the combination treatment was slightly more toxic than the two drugs given singly.

Cisplatin-based chemotherapy is currently recommended as the standard approach for patients with advanced NSCLC. However, to date, no prospective phase III study has explored the reproducibility of this benefit in elderly patients. Cisplatin administration is mainly associated with significant renal, neurological and gastrointestinal toxicity, and the evaluation of the risk versus benefit ratio should be particularly rigorous in elderly patients. The benefit of platinum doublet chemotherapy for the elderly is still controversial. Some investigators recommend single-agent chemotherapy with new-generation chemotherapeutic agents such as vinorelbine or gemcitabine on the basis of the evidence from some phase III trials [20] [24] [27]; on the other hand, others consider that platinum doublet chemotherapy is also acceptable for elderly patients, although the frequency and severity of the toxic effects associated with the latter are generally high [28].

In the elderly patient population, reduction of the creatinine clearance and cisplatin renal excretion is expected to increase the potential for toxicity, and the presence of comorbidities and compromised performance status may preclude cisplatin administration in a significant proportion of the elderly patients [29]. A retrospective analysis of cisplatin-based chemotherapy in NSCLC patients revealed a significant increase in the death rates within 30 days of starting the chemotherapy with increasing age $(0.5 \%, 3.3 \%, 3.2 \%, 7.1 \%$, and $12.5 \%$ for patients $\leq 54,55$ to 59, 60 to 64,65 to 69 , and $\geq 70$ years, respectively; $p=0.0001$ ) [30]. However, the frequency of renal toxicity after cisplatin administration to elderly patients has been studied by several authors, and with the exception of one study [31], the studies demonstrated an acceptable rate of renal function deterioration without a significant increase in age-related incidence [32]-[34]. These data support the feasibility of administering cisplatin to elderly patients, but the benefit of platinum-based combination chemotherapy (eventually modified in dose and/or schedule) should be proven by clinical trials specifically designed for elderly patients. These studies are still lacking, and evidence to support the use of platinum agents in elderly patients with advanced NSCLC comes only from several retrospective analyses of the subgroup of elderly patients enrolled in randomized trials without an upper age limit in the inclusion criteria [3] [28] [35]-[40].

Elderly patients were much less likely to receive chemotherapy, and they were more likely to receive nonplatinum chemotherapy regimens when they did receive chemotherapy. Elderly patient who received chemotherapy had significantly lower baseline (i.e., pretreatment) medical event rates, which reflected the selection of the fittest elders for treatment. Despite this selection, significantly higher adverse event rates were seen during the chemotherapy among the oldest age group compared to the youngest age group, and these rates reached $42.4 \%$ (95\% CI, $36.1 \%$ to $48.7 \%$ ) in patients age 65 to 74 years (RR, 1.70; 95\% CI, 1.19 to 2.43 ) before dropping 
slightly to $36 \%$ (95\% CI, $28.7 \%$ to $43.3 \%$ ) in patients age 75 years and older (RR, 1.34; $95 \%$ CI, 0.90 to 2.00 ) [41]. These findings are consistent with previous studies that showed that the elderly were much more likely to not receive therapy and that, when treated, the elderly were much more likely to receive less aggressive therapy [42]-[45]. None of these age relationships could be explained by a severity-adjusted measure of comorbidity.

Carboplatin shares a common mechanism of action with cisplatin but causes less nausea or vomiting, nephrotoxicity and neurotoxicity than does the latter drug and does not require hydration. Several randomized trials that have compared combination therapies based on carboplatin or cisplatin in indivisuals with advanced NSCLC have detected no significant differences in terms of the patient response rate and survival, whereas the toxicity of the platinum-based therapies was less than that of those based on cisplatin [5] [39] [46] [47]. These analyses show a similar outcome of platinum-based therapy for elderly patients compared to their younger counterparts, in terms of the response rate and overall survival, with a similar toxicity and nonsignificant adverse effect on the quality of life (as shown by Eastern Cooperative Oncology Group trial 5592 [28]. It is important to note, however, that the percentage of elderly patients enrolled in these studies with cisplatin did not exceed $20 \%$ of the actual study population.

A recent meta-analysis showed superior results in favor of cisplatin- versus carboplatin-based chemotherapy as the first-line treatment of advanced NSCLC [48]. In fact, in this meta-analysis, the authors showed a benefit in favor of cisplatin, but in a subgroup analysis restricted to the platinum-based chemotherapy with third-generation agents, a survival benefit in favor of cisplatin was reported. Moreover, although carboplatin causes lower rates of emesis, nephrotoxicity and neurotoxicity, it is associated with a higher hematological toxicity than cisplatin, particularly when combined with other myelotoxic drugs such as gemcitabine. Thus, in elderly patients, also safety remains a problem with the carboplatin-based chemotherapy. The issue of cisplatin- and carboplatin-based therapy for elderly patients with advanced NSCLC has been addressed in the retrospective analyses of large randomized trials [38]-[40] [46] [49] [50]. Treatment outcomes of patients younger and older than 70 years enrolled in these trials were compared. Overall, these analyses found no differences in survival between the elderly and younger patients, but, with a small but significant increase in toxicity in the elderly. Also, in the adjuvant setting, a recent pooled analysis found no effect of age on the outcomes of the cisplatin-based adjuvant chemotherapy [51]. This is a further finding that suggests that cisplatin-based chemotherapy should not be withheld from elderly patients with NSCLC purely on the basis of age.

Randomized trials demonstrate that chemotherapy improves the survival and quality of life in advanced NSCLC [23]. Two-drug platinum-based regimens (platinum doublets), generally a combination of cisplatin or carboplatin and another cytotoxic agent, demonstrate a survival advantage compared with single agents and are considered the standard of care for fit patients [46] [52]-[54]. The evidence of treatment efficacy for patients with diminished performance status or older than 70 years is limited, as these patients are frequently excluded from clinical trials due to the potential for toxicity and the expectation of limited benefit [55].

Three prospective randomized trials have investigated the optimal chemotherapy for elderly (70 years or older) NSCLC patients [20] [24] [56]. The Elderly Lung Cancer Vinorelbine Italian Study Group reported a significantly superior survival and quality of life with single-agent vinorelbine over the best supportive care (median survival time, 6.4 months and 4.8 months, respectively; $n=161$ ) [24]. Two other studies have attempted to determine whether doublet regimens are optimal over single-agent therapy in elderly patients [20] [56]. The conclusive results were reported in the Multicenter Italian Lung Cancer in the Elderly Study (MILES), which enrolled more than 700 patients and reported no significant survival difference between single-agent vinorelbine, single-agent gemcitabine, or a regimen with both agents combined [20].

In particular, the combination of carboplatin and paclitaxel is the most commonly used regimen for the treatment of advanced NSCLC and has been selected as the reference arm in several phase III trials [57] [58]. With regard to the carboplatin and paclitaxel combination, peripheral neuropathy, myalgia, arthralgia, and myelosuppression are the major clinical condition that distress patients and sometimes lead to treatment withdrawal. To minimize the occurrence of these toxic effects and to improve the tolerability of this regimen, a weekly schedule of paclitaxel has been evaluated and found to be associated with a reduction in the treatment toxicity and feasible therapeutic indices for patient with advanced NSCLC although these studies mainly included younger patients, while the benefit of such a regimen for elderly patients remains unknown [50] [59] [60].

For patients who are candidates for adjuvant therapy but are considered too high risk for platinum-based therapy, single-agent therapy may be a reasonable alternative, and is currently under investigation. A recently published meta-analysis by Des Guetz et al. [61] analyzed the benefit-to-risk ratio of doublet chemotherapy 
versus single-agent therapy in patients more than 70 years of age with advanced NSCLC [61]. The meta-analysis evaluated ten studies and included 2605 patients. Toxicity was found to be significantly more frequent in patients receiving doublets, compared to single-agent therapy; but no difference was found in the 1-year overall survival [61].

Our two regimens, the GC and PC regimens, were frequently selected for inoperable advanced lung cancer in clinical practice. In our carboplatin-based chemotherapy setting for elderly patients with the resected NSCLC, grade 3/4 thrombocytopenia was significantly observed in the GC regimen compared to those in the PC regimen. The nonhematological toxicities were mild except for infection. Grade 4 pneumonia was observed in 1 patient $(1 / 15,6.7 \%)$ of the PC regimen compared to none in the GC regimen. Grade 1/2 alanine aminotransferase and aspartate aminotransferase (ALT/AST) in the GC regimen were significantly more observed compared to those of the PC regimen. Grade 1/2 alopecia was significantly more observed in the GC regimen. Strengths and limitations of this retrospective study are suggested to be the data from a small number of surgical Japanese patients in clinical practice and to be preliminary outcomes from elderly NSCLC patients to perform the next randomized perspective study.

Based on the results of our above-mentioned clinical outcomes, the toxicities of the GC regimen and PC regimen for the elderly patients in NSCLC were different, however, both regimens were feasible and safely performed. The GC and PC regimens were well tolerated, and there were no chemotherapy-related deaths. Accordingly, the GC and PC regimens could be considered as a treatment option for Japanese elderly patients.

\section{References}

[1] Owonikoko, T.K., Ragin, C.C., Belani, C.P., Oton, A.B., Gooding, W.E., Taioli, E. and Ramalingam, S.S. (2007) Lung Cancer in Elderly Patients: An Analysis of the Surveillance, Epidemiology, and End Results Database. Journal of Clinical Oncology, 25, 5570-5577. http://dx.doi.org/10.1200/JCO.2007.12.5435

[2] National Institute of Population and Social Security Research (2005) Population Projections for Japan. 2001-2050. http://www.ipss.go.jp

[3] Gridelli, C. and Shepherd, F.A. (2005) Chemotherapy for Elderly Patients with Non-Small Cell Lung Cancer: A Review of the Evidence. Chest, 128, 947-957. http://dx.doi.org/10.1378/chest.128.2.947

[4] Non-Small Cell Lung Cancer Collaborative Group (1995) Chemotherapy in Non-Small Cell Lung Cancer: A Meta-Analysis Using Updated Data on Individual Patients from 52 Randomised Clinical Trials. BMJ, 311, 899-909. http://dx.doi.org/10.1136/bmj.311.7010.899

[5] Schiller, J.H., Harrington, D., Belani, C.P., Langer, C., Sandler, A., Krook, J., Zhu, J. and Johnson, D.H. (2002) Eastern Cooperative Oncology Group. Comparison of Four Chemotherapy Regimens for Advanced Non-Small-Cell Lung Cancer. The New England Journal of Medicine, 346, 92-98. http://dx.doi.org/10.1056/NEJMoa011954

[6] Kubota, K., Nishiwaki, Y., Ohashi, Y., Saijo, N., Ohe, Y., Tamura, T., Negoro, S., Ariyoshi, Y., Nakagawa, K. and Fukuoka, M. (2004) The Four-Arm Cooperative Study (FACS) for Advanced Non-Small-Cell Lung Cancer (NSCLC). Proceeding of the American Society of Clinical Oncology, 22, 14S.

[7] Hutchins, L.F., Unger, J.M., Crowley, J.J., Coltman, C.A. and Albain Jr., K.S. (1999) Underrepresentation of Patients 65 Years of Age or Older in Cancer-Treatment Trials. The New England Journal of Medicine, 341, 2061-2067. http://dx.doi.org/10.1056/NEJM199912303412706

[8] Sobin, L.H. and Fleming, I.D. (1997) TNM Classification of Malignant Tumors, fifth Edition (1997). Union Internationale Contre le Cancer and the American Joint Committee on Cancer. Cancer, 80, 1803-1804.

[9] Travis, W.D., Garg, K., Franklin, W.A., Wistuba, I.I., Sabloff, B., Noguchi, M., Kakinuma, R., Zakowski, M., Ginsberg, M., Padera, R., et al. (2006) Bronchioloalveolar Carcinoma and Lung Adenocarcinoma: The Clinical Importance and Research Relevance of the 2004 World Health Organization Pathologic Criteria. Journal of Thoracic Oncology, 1, S13-19. http://dx.doi.org/10.1097/01243894-200611001-00004

[10] Calvert, A.H., Newell, D.R., Gumbrell, L.A., O’Reilly, S., Burnell, M., Boxall, F.E., Siddik, Z.H., Judson, I.R., Gore, M.E. and Wiltshaw, E. (1989) Carboplatin Dosage: Prospective Evaluation of a Simple Formula Based on Renal Function. Journal of Clinical Oncology, 7, 1748-1756.

[11] Cockcroft, D.W. and Gault, M.H. (1976) Prediction of Creatinine Clearance from Serum Creatinine. Nephron, 16, 31-41.

[12] Therasse, P., Arbuck, S.G., Eisenhauer, E.A., Wanders, J., Kaplan, R.S., Rubinstein, L., Verweij, J., Van Glabbeke, M., van Oosterom, A.T., Christian, M.C. and Gwyther, G. (2000) New Guidelines to Evaluate the Response to Treatment in Solid Tumors. European Organization for Research and Treatment of Cancer, National Cancer Institute of the United States, National Cancer Institute of Canada. Journal of the National Cancer Institute, 92, 205-216. 
http://dx.doi.org/10.1093/jnci/92.3.205

[13] Parkin, D.M., Bray, F., Ferlay, J. and Pisani, P. (2001) Estimating the World Cancer Burden: Globocan 2000. International Journal of Cancer, 94, 153-156. http://dx.doi.org/10.1002/ijc.1440

[14] Mun, M. and Kohno, T. (2008) Video-Assisted Thoracic Surgery for Clinical Stage I Lung Cancer in Octogenarians. Annals of Thoracic Surgery, 85, 406-411. http://dx.doi.org/10.1016/j.athoracsur.2007.10.057

[15] Cattaneo, S.M., Park, B.J., Wilton, A.S., Seshan, V.E., Bains, M.S., Downey, R.J., Flores, R.M., Rizk, N. and Rusch, V.W. (2008) Use of Video-Assisted Thoracic Surgery for Lobectomy in the Elderly Results in Fewer Complications. Annals of Thoracic Surgery, 85, 231-236. http://dx.doi.org/10.1016/j.athoracsur.2007.07.080

[16] Gridelli, C., Perrone, F. and Monfardini, S. (1997) Lung Cancer in the Elderly. European Journal of Cancer, 33, 2313-2314. http://dx.doi.org/10.1016/S0959-8049(97)10050-8

[17] Repetto, L. and Balducci, L. (2002) A Case for Geriatric Oncology. Lancet Oncology, 3, 289-297. http://dx.doi.org/10.1136/bmj.311.7010.899

[18] Repetto, L., Venturino, A., Fratino, L., Serraino, D., Troisi, G., Gianni, W. and Pietropaolo, M. (2003) Geriatric Oncology: A Clinical Approach to the Older Patient with Cancer. European Journal of Cancer, 39, 870-880. http://dx.doi.org/10.1016/S0959-8049(03)00062-5

[19] Fentiman, I.S., Tirelli, U., Monfardini, S., Schneider, M., Festen, J., Cognetti, F. and Aapro, S. (1990) Cancer in the Elderly: Why So Badly Treated? Lancet, 335, 1020-1022. http://dx.doi.org/10.1016/0140-6736(90)91075-L

[20] Gridelli, C., Perrone, F., Gallo, C., Cigolari, S., Rossi, A., Piantedosi, F., Barbera, S., Ferraù, F., Piazza, E., Rosetti, F., Clerici, M., Bertetto, O., Robbiati, S. F., Frontini, L., Sacco, C., Castiglione, F., Favaretto, A., Novello, S., Migliorino, M.R., Gasparini, G., Galetta, D., Iaffaioli, R.V. and Gebbia, V. (2003) MILES Investigators. Chemotherapy for Elderly Patients with Advanced Non-Small-Cell Lung Cancer: The Multicenter Italian Lung Cancer in the Elderly Study (MILES) Phase III Randomized Trial. Journal of National Cancer Institute, 95, 362-372. http://dx.doi.org/10.1093/jnci/95.5.362

[21] Di Maio, M., Perrone, F., Gallo, S., Iaffaioli, R.V., et al. (2003) Supportive Care in Patients with Advanced NonSmall-Cell Lung Cancer. British Journal of Cancer, 89, 1013-1021. http://dx.doi.org/10.1038/sj.bjc.6601236

[22] Lewis, J.H., Kilgore, M.L., Goldman, D.P., Trimble, E.L., Kaplan, R., Montello, M.J., Housman, M.G. and Escarce, J.J. (2003) Participation of Patients 65 Years of Age or Older in Cancer Clinical Trials. Journal of Clinical Oncology, 21, 1383-1389. http://dx.doi.org/10.1200/JCO.2003.08.010

[23] Pfister, D.G., Johnson, D.H., Azzoli, C.G., Sause, W., Smith, T.J., Baker Jr., S., Olak, J., Stover, D., Strawn, J.R., Turrisi, A.T. and Somerfield, M.R. (2004) American Society of Clinical Oncology. American Society of Clinical Oncology Treatment of Unresectable Non-Small-Cell Lung Cancer Guideline: Update 2003. Journal of Clinical Oncology, 22, 330-353. http://dx.doi.org/10.1200/JCO.2004.09.053

[24] The Elderly Lung Cancer Vinorelbine Italian Study Group (1999) Effects of Vinorelbine on Quality of Life and Survival of Elderly Patients with Advanced Non-Small-Cell Lung Cancer. Journal of National Cancer Institute, 91, 66-72. http://dx.doi.org/10.1093/jnci/91.1.66

[25] Gridelli, C., Cigolari, S., Gallo, C., Manzione, L., Ianniello, G.P., Frontini, L., Ferraù, F., Robbiati, S.F., Adamo, V., Gasparini, G., Novello, S. and Perrone, F. (2001) MILES Investigators. Activity and Toxicity of Gemcitabine and Gemcitabine + Vinorelbine in Advanced Non-Small-Cell Lung Cancer Elderly Patients: Phase II Data from the Multicenter Italian Lung Cancer in the Elderly Study (MILES) Randomized Trial. Lung Cancer, 31, 277-284. http://dx.doi.org/10.1016/S0169-5002(00)00194-X

[26] Fidias, P., Supko, J.G., Martins, R., Boral, A., Carey, R., Grossbard, M., Shapiro, G., Ostler, P., Lucca, J., Johnson, B.E., Skarin, A. and Lynch, T.J. (2001) A Phase II Study of Weekly Paclitaxel in Elderly Patients with Advanced Non-Small Cell Lung Cancer. Clinical Cancer Research, 7, 3942-3949.

[27] Kudoh, S., Takeda, K., Nakagawa, K., Takada, M., Katakami, N., Matsui, K., Shinkai, T., Sawa, T., Goto, I., Semba, H., Seto, T., Ando, M., Satoh, T., Yoshimura, N., Negoro, S. and Fukuoka, M. (2006) Phase III Study of Docetaxel Compared with Vinorelbine in Elderly Patients with Advanced Non-Small-Cell Lung Cancer: Results of the West Japan Thoracic Oncology Group Trial (WJTOG 9904). Journal of Clinical Oncology, 24, 3657-3663. http://dx.doi.org/10.1200/JCO.2006.06.1044

[28] Langer, C.J. (2002) Elderly Patients with Lung Cancer: Biases and Evidence. Current Treatment Options Oncology, 3, 85-102. http://dx.doi.org/10.1007/s11864-002-0045-9

[29] Oshita, F., Kurata, T., Kasai, T., Fakuda, M., Yamamoto, N., Ohe, Y., Tamura, T., Eguchi, K., Shinkai, T. and Saijo, N. (1995) Prospective Evaluation of the Feasibility of Cisplatin-Based Chemotherapy for Elderly Lung Cancer Patients with Normal Organ Functions. Japanese Journal of Cancer Research, 86, 1198-1202. http://dx.doi.org/10.1111/j.1349-7006.1995.tb03315.x

[30] Rinaldi, M., De Marinis, F., Ardizzoni, A., et al. (1994) Correlation between Age and Prognosis in Patients with Ad- 
vanced Non Small Cell Lung Cancer Treated with Cisplatin Containing Chemotherapy: A Retrospective Multicentre Study. Annals of Oncology, $\mathbf{5 8 .}$.

[31] Kubota, K., Hosomura, K., Kakinuma, R., et al. (1998) Cisplatin Nephrotoxicity in Elderly Patients with Lung Cancer. Proceeding of the American Society of Clinical Oncology, 17, 491a.

[32] Thyss, A., Saudes, L., Otto, J., Creisson, A., Gaspard, M.H., Dassonville, O. and Schneider, M. (1994) Renal Tolerance of Cisplatin in Patients More Than 80 Years Old. Journal of Clinical Oncology, 12, 2121-2125.

[33] Cubillo, A., Cornide, M., López, J.L., Molina, R., Feliu, J., Espinosa, E., Zamora, P., de Castro, J., Ordoñez, A. and González Barón, M. (2001) Renal Tolerance to Cisplatin in Patients 70 Years and Older. American Journal of Clinical Oncology, 24, 192-197. http://dx.doi.org/10.1097/00000421-200104000-00018

[34] Nguyen, B., Sandler, A. and Denham, C. (1999) The Safety and Efficacy of Gemcitabine Plus Cisplatin in the Elderly Chemo-Naïve NSCLC Patients (Age $\geq 70$ Years) as Compared to Those with Age $<70$ Years. Proceeding of the American Society of Clinical Oncology, 18, 471a.

[35] Kelly, K., Crowley, J., Bunn, P.A., Presant Jr., C.A., Grevstad, P.K., Moinpour, C.M., Ramsey, S.D., Wozniak, A.J., Weiss, G.R., Moore, D.F., Israel, V.K., Livingston, R.B. and Gandara, D.R. (2001) Randomized Phase III Trial of Paclitaxel plus Carboplatin versus Vinorelbine plus Cisplatin in the Treatment of Patients with Advanced Non-Small-Cell Lung Cancer: A Southwest Oncology Group Trial. Journal of Clinical Oncology, 19, 3210-3218.

[36] Lilenbaum, R.C., Herndon, J., List, M., et al. (2002) Single-Agent (SA) vs Combination Chemotherapy (CC) in Advanced Non-Small Cell Lung Cancer (NSCLC): A CALGB Randomized Trial of Efficacy, Quality of Life (QoL), and CostEffectiveness. Proceeding of the American Society of Clinical Oncology, 21, 1a.

[37] Rocha Lima, C.M., Herndon II, J.E., Kosty, M., Clamon, G. and Green, M.R. (2002) Therapy Choices among Older Patients with Lung Carcinoma: An Evaluation of Two Trials of the Cancer and Leukemia Group B. Cancer, 94, 181187. http://dx.doi.org/10.1002/cncr.10174

[38] Langer, C.J., Vangel, J., Schiller, D.P., et al. (2003) Age-Specific Subanalysis of ECOG 1594: Fit Elderly Patients (70-80 yrs) with NSCLC Do as Well as Younger Patients (<70). Proceeding of the American Society of Clinical Oncology, 22, 639.

[39] Fossella, F.V. and Belani, C.P. (2003) Phase II Study (TAX 326) of Docetaxel-Cisplatin (DC) and Docetaxel-Carboplatin (DCb) versus Vinorelbine-Cisplatin (VC) for the First-Line Treatment of Advanced/Metastatic Non-Small-Cell-Lung Cancer (NSCLC): Analysis in Elderly Patients. Proceeding of the American Society of Clinical Oncology, 22, 629.

[40] Hensing, T.A., Peterman, A.H., Schell, M.J., Lee, J.H. and Socinski, M.A. (2003) The Impact of Age on Toxicity, Response Rate, Quality of Life, and Survival in Patients with Advanced, Stage IIIB or IV Nonsmall Cell Lung Carcinoma Treated with Carboplatin and Paclitaxel. Cancer, 98, 779-788. http://dx.doi.org/10.1002/cncr.11548

[41] Chrischilles, E.A., Pendergast, J.F., Kahn, K.L., Wallace, R.B., Moga, D.C., Harrington, D.P., Kiefe, C.I., Weeks, J.C., West, D.W., Zafar, S.Y. and Fletcher, R.H. (2010) Adverse Events among the Elderly Receiving Chemotherapy for Advanced Non-Small-Cell Lung Cancer. Journal of Clinical Oncology, 28, 620-627. http://dx.doi.org/10.1200/JCO.2009.23.8485

[42] Potosky, A.L., Saxman, S., Wallace, R.B. and Lynch, C.F. (2004) Population Variations in the Initial Treatment of Non-Small-Cell Lung Cancer. Journal of Clinical Oncology, 22, 3261-3268. http://dx.doi.org/10.1200/JCO.2004.02.051

[43] Earle, C.C., Tsai, J.S., Gelber, R.D., Weinstein, M.C., Neumann, P.J. and Weeks, J.C. (2001) Effectiveness of Chemotherapy for Advanced Lung Cancer in the Elderly: Instrumental Variable and Propensity Analysis. Journal of Clinical Oncology, 19, 1064-1070.

[44] Smith, T.J., Penberthy, L., Desch, C.E., Whittemore, M., Newschaffer, C., Hillner, B.E., McClish, D. and Retchin, S.M. (1995) Differences in Initial Treatment Patterns and Outcomes of Lung Cancer in the Elderly. Lung Cancer, 13, 235252. http://dx.doi.org/10.1016/0169-5002(95)00496-3

[45] Ramsey, S.D., Howlader, N., Etzioni, R.D. and Donato, B. (2004) Chemotherapy Use, Outcomes, and Costs for Older Persons with Advanced Non-Small-Cell Lung Cancer: Evidence from Surveillance, Epidemiology and End ResultsMedicare. Journal of Clinical Oncology, 22, 4971-4978. http://dx.doi.org/10.1200/JCO.2004.05.031

[46] Kelly, K., Giarritta, S., Akerley, W., et al. (2001) Should Older Patient (pts) Receive Combination Chemotherapy for Advanced Stage Non-Small Cell Lung Cancer (NSCLC)? An Analysis of Southwest Oncology Trials 9509 and 9308. Proceeding of the American Society of Clinical Oncology, 20, 329a.

[47] Mazzanti, P., Massacesi, C., Rocchi, M.B., Mattioli, R., Lippe, P., Trivisonne, R., Buzzi, F., De Signoribus, G., Tuveri, G., Rossi, G., Di Lullo, L., Sturba, F., Morale, D., Catanzani, S., Pilone, A., Bonsignori, M. and Battelli, T. (2003) Randomized, Multicenter, Phase II Study of Gemcitabine Plus Cisplatin versus Gemcitabine Plus Carboplatin in Patients with Advanced Non-Small Cell Lung Cancer. Lung Cancer, 41, 81-89. http://dx.doi.org/10.1016/S0169-5002(03)00140-5 
[48] Ardizzoni, A., Boni, L., Tiseo, M., Fossella, F.V., Schiller, J.H., Paesmans, M., Radosavljevic, D., Paccagnella, A., Zatloukal, P., Mazzanti, P., Bisset, D. and Rosell, R. for CISCA (CISplatin versus CArboplatin) Meta-Analysis Group (2007) Cisplatin- versus Carboplatin-Based Chemotherapy in First-Line Treatment of Advanced Non-Small-Cell Lung Cancer: An Individual Patient Data Meta-Analysis. Journal of National Cancer Institute, 99, 847-857. http://dx.doi.org/10.1093/jnci/djk196

[49] Lilenbaum, R.C., Herndon II, J.E., List, M.A., Desch, C., Watson, D.M., Miller, A.A., Graziano, S.L., Perry, M.C., Saville, W., Chahinian, P., Weeks, J.C., Holland, J.C. and Green, M.R. (2005) Single-Agent versus Combination Chemotherapy in Advanced Non-Small-Cell Lung Cancer: The Cancer and Leukemia Group B (Study 9730). Journal of Clinical Oncology, 23, 190-196. http://dx.doi.org/10.1200/JCO.2005.07.172

[50] Belani, C.P., Barstis, J., Perry, M.C., La Rocca, R.V., Nattam, S.R., Rinaldi, D., Clark, R. and Mills, G.M. (2003) Multicenter, Randomized Trial for Stage IIIB or IV Non-Small-Cell Lung Cancer Using Weekly Paclitaxel and Carboplatin Followed by Maintenance Weekly Paclitaxel or Observation. Journal of Clinical Oncology, 21, 2933-2939. http://dx.doi.org/10.1200/JCO.2003.02.563

[51] Früh, M., Rolland, E., Pignon, J.P., Seymour, L., Ding, K., Tribodet, H., Winton, T., Le Chevalier, T., Scagliotti, G.V., Douillard, J.Y., Spiro, S. and Shepherd, F.A. (2008) Pooled Analysis of the Effect of Age on Adjuvant Cisplatin-Based Chemotherapy for Completely Resected Non-Small-Cell Lung Cancer. Journal of Clinical Oncology, 26, 3573-3581.

[52] Wozniak, A.J., Crowley, J.J., Balcerzak, S.P., Weiss, G.R., Spiridonidis, C.H., Baker, L.H., Albain, K.S., Kelly, K., Taylor, S.A., Gandara, D.R. and Livingston, R.B. (1998) Randomized Trial Comparing Cisplatin with Cisplatin Plus Vinorelbine in the Treatment of Advanced Non-Small-Cell Lung Cancer: A Southwest Oncology Group Study. Journal of Clinical Oncology, 16, 2459-2465.

[53] Sandler, A.B., Nemunaitis, J., Denham, C., von Pawel, J., Cormier, Y., Gatzemeier, U., Mattson, K., Manegold, C., Palmer, M.C., Gregor, A., Nguyen, B., Niyikiza, C. and Einhorn, L.H. (2000) Phase III Trial of Gemcitabine Plus Cisplatin versus Cisplatin Alone in Patients with Locally Advanced or Metastatic Non-Small-Cell Lung Cancer. Journal of Clinical Oncology, 18, 122-130.

[54] Schiller, J.H., Harrington, D., Belani, C.P., Langer, C., Sandler, A., Krook, J., Zhu, J. and Johnson, D.H. for Eastern Cooperative Oncology Group (2002) Comparison of Four Chemotherapy Regimens for Advanced Non-Small-Cell Lung Cancer. The New England Journal of Medicine, 346, 92-98. http://dx.doi.org/10.1056/NEJMoa011954

[55] Gridelli, C., Langer, C., Maione, P., Rossi, A. and Schild, S.E. (2007) Lung Cancer in the Elderly. Journal of Clinical Oncology, 25, 1898-1907. http://dx.doi.org/10.1200/JCO.2006.10.3085

[56] Frasci, G., Lorusso, V., Panza, N., Comella, P., Nicolella, G., Bianco, A., De Cataldis, G., Iannelli, A., Bilancia, D., Belli, M., Massidda, B., Piantedosi, F., Comella, G. and De Lena, M. (2000) Gemcitabine Plus Vinorelbine versus Vinorelbine Alone in Elderly Patients with Advanced Non-Small-Cell Lung Cancer. Journal of Clinical Oncology, 18, 2529-2536.

[57] Sandler, A., Gray, R., Perry, M.C., Brahmer, J., Schiller, J.H., Dowlati, A., Lilenbaum, R. and Johnson, D.H. (2006) Paclitaxel-Carboplatin Alone or with Bevacizumab for Non-Small-Cell Lung Cancer. The New England Journal of Medicine, 355, 2542-2550. http://dx.doi.org/10.1056/NEJMoa061884

[58] Kubota, K., Kawahara, M., Ogawara, M., Nishiwaki, Y., Komuta, K., Minato, K., Fujita, Y., Teramukai, S., Fukushima, M. and Furuse, K. on Behalf of the Japan Multi-National Trial Organisation (2008) Vinorelbine Plus Gemcitabine Followed by Docetaxel versus Carboplatin Plus Paclitaxel in Patients with Advanced Non-Small-Cell Lung Cancer: A Randomised, Open-Label, Phase III Study. Lancet Oncology, 9, 1135-1142. http://dx.doi.org/10.1016/S1470-2045(08)70261-4.

[59] Hirabayashi, M., Endoh, K., Teramachi, M., Okuda, M., Yamaguchi, K., Fukuda, K., Tokuhisa, H., Kagioka, H., Nakai, N. and Nakade, M. (2004) Phase II Study of Carboplatin and Weekly Paclitaxel Combination Chemotherapy in Advanced Non-Small Cell Lung Cancer: A Kansai Clinical Oncology Group Study. Lung Cancer, 44, 355-362. http://dx.doi.org/10.1016/j.lungcan.2003.12.001

[60] Belani, C.P., Ramalingam, S., Perry, M.C., LaRocca, R.V., Rinaldi, D., Gable, P.S. and Tester, W.J. (2008) Randomized, Phase III Study of Weekly Paclitaxel in Combination with Carboplatin versus Standard Every-3-Weeks Administration of Carboplatin and Paclitaxel for Patients with Previously Untreated Advanced Non-Small-Cell Lung Cancer. Journal of Clinical Oncology, 26, 468-473. http://dx.doi.org/10.1200/JCO.2007.13.1912

[61] Des Guetz, G., Uzzan, B., Nicolas, P., Valeyre, D., Sebbane, G. and Morere, J.F. (2012) Comparison of the Efficacy and Safety of Single-Agent and Doublet Chemotherapy in Advanced Non-Small Cell Lung Cancer in the Elderly: A Meta-Analysis. Critical Reviews in Oncology/Hematology, 84, 340-349. http://dx.doi.org/10.1016/j.critrevonc.2012.03.007 


\section{Abbreviations}

Non-Small Cell Lung Cancer (NSCLC);

Gemcitabine plus carboplatin (GC);

Paclitaxel plus carboplatin (PC);

Tumor Node Metastasis (TNM);

Disseminated intravascular coagulation (DIC) 